\title{
Quiste folicular gigante luteinizado del embarazo y el puerperio. Presentación de un caso y revisión de la literatura
}

\author{
Lilia Sánchez MD.*; Juan Carlos Sabogal**
}

Recibido: Abril 6/2000

Revisado: Abril $24 / 2000$

Aceptado: Agosto $11 / 2000$

\section{RESUMEN}

Mujer de 23 años con embarazo de 37 semanas de EG y diagnóstico ecográfico de masa quística anexial derecha clínicamente benigna, quien fue llevada a cesarea para atención del parto $t$ reseccion de la masa. El estudio anatomopatologico del tumor mostró un quiste folicular Gigante Solitario Luteinizado (QFGSL) del embarazo. El manejo quirúrgico de la paciente fue conservador, con una evolución adecuada y óptimo pronóstico. Se discuten los aspectos referentes a la historia natural de la enfermedad, las características anatomopatológicas y la posible patogenia.

PALABRAS CLAVES: Quiste gigante solitario luteinizado del embarazo, masas anexiales, embarazo y masas anexiales.

\section{SUMMARY}

We wish to present a case of a patient seen at our hospital at 37 weeks gestation with an adnexal mass. Patient was taken to cesarean and physiopathology.

KEY WORDS: Large luteinized follicular Cyst of Pregnancy, Adnexal Masses, Pregnancy and adnexal masses.

\section{Introducción}

Los tumores de ovario que se manifiestan durante el embarazo tienen una frecuencia que puede variar entre 1:653 y 1:1000, la mayoría son benignos y tienen origen epitelial o germinal, a diferencia de estos, son raras las lesiones no neoplásicas del ovario que llegan a manifestarse como complicación durante la gestación (1). En esta ocasión presentamos el hallazgo de un Quiste Folicular Gigante Solitario Luteinizado (QFGSL) del embarazo, del cual han sido pocos los casos reportados en la literatura, sin embargo dado el tamaño que llegan a alcanzar pueden complicar el embarazo, la atención del parto y el puerperio, y plantear el diagnóstico inicial de lesión neoplásica.

Caso

Mujer de 23 años G3 P2 AO, menarquia a los 17 años, I.R.S: 16 años. Remitida al Instituto Materno Infantil (1MI) a las 37 semanas de edad gestacional para atención del parto. Antecedentes: cesárea segmentaria transperitoneal por presentación podálica, endometritis pos cesárea, fumadora de 2-3 cigarrillos/día, tomo sulfato ferroso 300 $\mathrm{mg} /$ día durante la gestación. Al ingreso se encontró T A
100/54, FC: 60', FR: 16', afebril, útero grávido, AV: $32 \mathrm{~cm}$, FCF: 140', feto único vivo, longitudinal, cefálico con dorso anterior derecho. Se le realizó una ecografía que mostró una gestación a término y una masa de ecogenicidad mixta, anexial derecha de $14.1 \times 7.8 \mathrm{~cm}$, que ocupaba el flanco y el hipocondrio derecho. El CH mostró $\mathrm{Hb} 12.5$ g/ dI, Leucocitos: 7.500, N: $70.3 \%$, L: 24\%, M: 4\%, recuento de plaquetas: 228.000. Serología VDRL: no reactiva. Fue valorada por el servicio de Oncología y se decidió llevar a CSTP y cistectomía con diagnóstico de Quiste Dermoide. Se realizó salpingo-ooforectomía y la impresión diagnóstica en el postoperatorio fue Cistoadenoma Seroso. En patología se recibió un quiste previamente abierto cuya pared midió 12 x $9 \mathrm{~cm}$ y tenía un espesor de $0.4 \mathrm{~cm}$. La superficie externa como la interna eran lisas, la primera blanco nacarado y la segunda amarillenta (Fig. 0023i01). La trompa uterina midió 5 x $0.6 \mathrm{~cm}$ y no presentaba alteraciones. El estudio microscópico mostró la pared de un quiste de tejido fibroconectivo tapizada por hasta 10 capas de células luteinizadas, las cuales varían de tamaño y forma y tienen un citoplasma abundante eosinófilo o pálido vacuolado (Fig. 0023i02). La citología de la gotera parietocólica derecha e izquierda, la cúpula subdiafragmatica

* Profesora Asistente, Departamento de Patología, Facultad de Medicina, Universidad Nacional de Colombia, Instituto Materno Infantil, Bogotá.

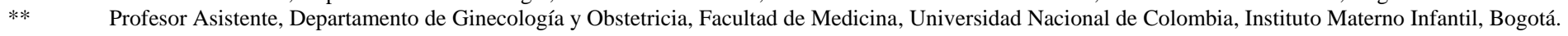


Fig. 0023i01

PARED DE QUISTE CON SUPERFICIE EXTERNA E
INTERNA LISAS. LA SUPERFICIE EXTERNA ES
BLANQUECINA, LA INTERNA ES AMARILLENTA.

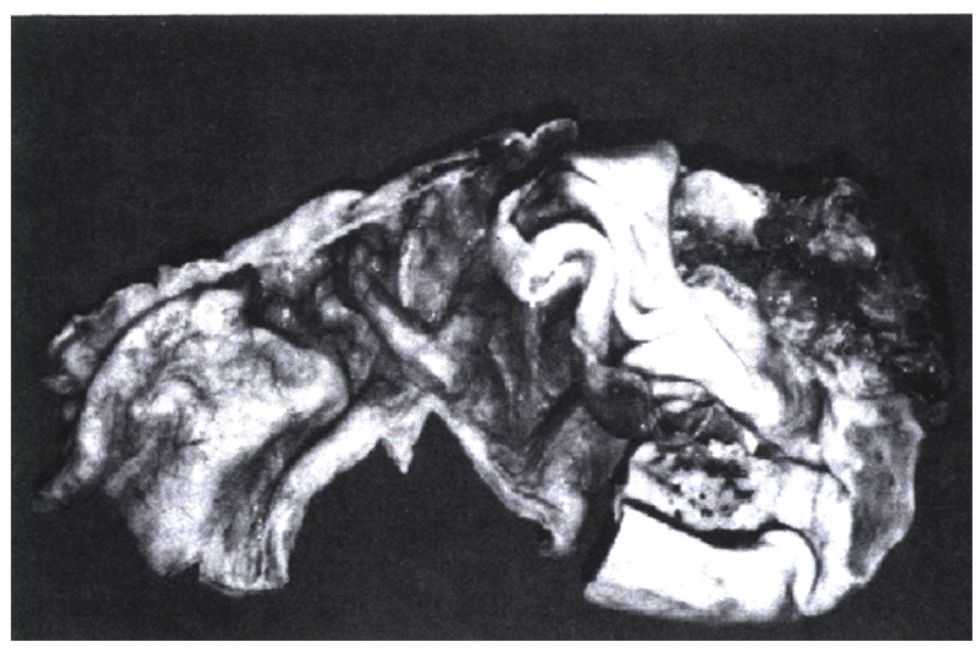

diafragmática derecha e izquierda y del líquido peritoneal negativa, solo se evidenciaron algunas, células mesoteliales reactivas. El diagnóstico anatomopatológico fue QFGSL.

\section{Discusión}

Durante el embarazo y el puerperio, se han visto folículos solitarios quísticos que han llegado a alcanzar un diámetro mayor de $25 \mathrm{~cm}$, por lo que han recibido la denominación de Quiste Folicular Gigante Solitario Luteinizado (QFGSL), a diferencia de los Quistes Foliculares Solitarios vistos en ausencia de embarazo que solo alcanzan un diámetro de $8 \mathrm{~cm}$. El primer reporte de QFGSL fue en 1976 por Albukerk y Berlibnya (2), luego fue en 1980 que Clement y Scully (3) reportaron 8 casos de QFGSL unilateral de ovario que habían sido detectados durante el embarazo o el puerperio, posteriormente en 1981 Kott y Schmidt (4) reportaron otro. Debido al tamaño que pueden alcanzar estos quistes puede ocasionar distensión abdominal, sin embargo usualmente son un hallazgo incidental en el momento de la cesárea o durante el primer examen de control en el puerperio. Generalmente son uniloculares, unilaterales, tienen una pared delgada y su contenido es un líquido claro. En el examen histopatológico la cápsula del quiste está revestida por un máximo de 10 capas de células foliculares luteinizadas, las cuales tienen la característica de variar de tamaño y forma además de mostrar un citoplasma abundante eosinófilo o pálido vacuolado. Aunque la mayoría de los núcleos son redondos y claros, también se pueden ver focalmente núcleos grandes, pleomórficos e hipercromáticos, que no muestran mitosis. Las células luteinlzadas también pueden verse dentro del tejido fibroso de la pared del quiste (5).

El QFGSL del embarazo es una lesión poco frecuente del ovario, si bien hay otras lesiones no neoplásicas que se observan con mayor frecuencia como el folículo quístico solitario (FQS) este se ve durante la edad reproductiva especialmente en los años que siguen a la menarquia y en los que anteceden a la menopausia. En estos casos la
Fig. $0023 i 02$

\section{H\&E 100X. PARED DE QUISTE TAPIZADA POR MULTIPLES CAPAS DE CÉLULAS FOLICULARES LUTEINIZADAS, ALGUNAS CON NUCLEOS ATIPICOS.}

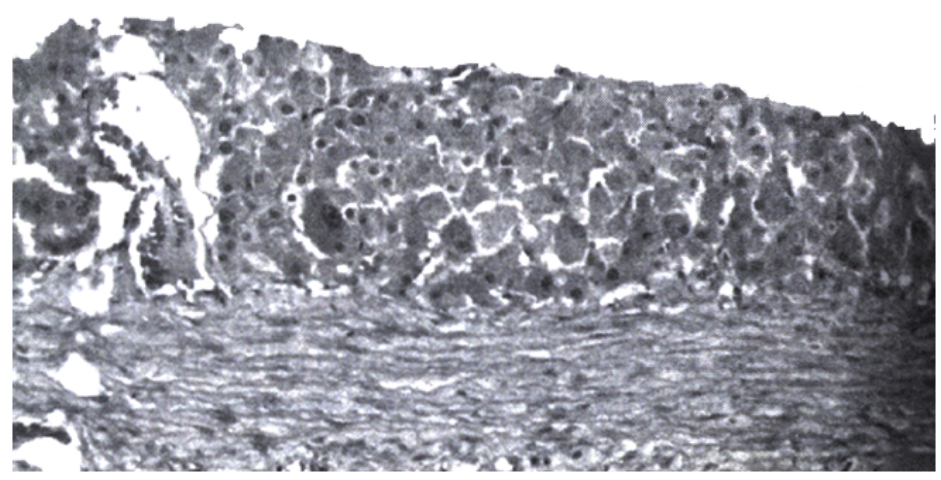

quistificación del folículo ocurre por él estimulo hormonal continuo de un folículo en desarrollo por la gonadotrofina a mitad del ciclo en ausencia del pico de la hormona luteinizante (HL), la cual normalmente actúa estimulando la ovulación. La incidencia real de estos quistes no está bien establecida pues muchos de estos reciben tratamiento médico o involucionan espontáneamente y suelen manifestarse como una hemorragia uterina anormal o un hemoperitoneo secundario a ruptura espontánea. Otros son los folículos quísticos que son tan frecuentes y se consideran fisiológicos (6-7).

La asociación de este quiste con el embarazo sugiere una relación en su patogénesis con la hCG. En cuatro de los casos reportados, sin embargo la lesión fue diagnosticada hasta seis semanas después del parto cuando los niveles de hCG no son detectables (8-9). Clement y Scully postularon que en estos casos los quistes pudieron haber surgido durante el embarazo sin ser detectados, aumentando de tamaño durante el puerperio como resultado de los niveles altos de las Gonadotrofinas de la Adenohipófisis (5).

El diagnóstico diferencial de este tumor incluye el Cuerpo Luteo Quístico (CLQ) y las formaciones quísticas uniloculares de los Tumores de Células de la Granulosa (TCG). El CL del embarazo aunque con frecuencia es quístico no llega a alcanzar un diámetro mayor de $6 \mathrm{~cm}$ y es de forma con voluta, en estos se puede ver con claridad la diferencia entre la capa de células de la granulosa y la teca luteínica, pueden apreciarse además cuerpos hialinos y pequeños cuerpos calcificados, también carece del pleomorfismo visto en los QFGSL (4-5). El TCG quístico y unilocular puede simular a este quiste tanto macro como microscópicamente, sin embargo carece de núcleos bizarros y muestra en su pared las células típicas de la granulosa, es excepcional que estas células se luteinizen uniformemente. Se cree que probablemente este tumor representa una forma inusual de TCG, pero el seguimiento en los casos encontrados hasta el momento sugiere que es solo otro tipo de lesión no neoplásica relacionada con el embarazo (5-10). 


\section{Conclusión}

Aun cuando el QFGSL del embarazo y el embarazo es muy poco frecuente, es importante tenerlo en cuanto en el diagnóstico diferencial de las lesiones quísticas que se puedan llegar a encontrar en el embarazo, el parto y el puerperio. El desconocimiento de su naturaleza en algún momento podría llevar a la ejecución de conductas médicoquirúrgicas agresivas innecesarias.

\section{BIBLIOGRAFIA}

1. DiSaia JP, Creasman TW. Clinical Gynecologic Oncology. Mosby. Fifth Edition. 1997; 452-457.

2. Albvukerk JN, Berlin M. Unilateral lutein cyst in pregnancy. New York State Joumal of Medicine. 1976; 76: 259-261.

3. Clement PB, Scully RE. Large solitary luteinized follicular cyst of pregnancy and puerperium: a clinicopathological analysis of eigth cases. American Joumal of Surgical Pathology. 1980; 4: 431-438.

4. Kott MM, Schmidt W A. Massive postpartum corpus luteum cyst: a case report. Human Pathology. 1981; 12: 468-470.

5. Young RH, Scully RE. Non-neoplastico disorders of the ovary in: Haines \& Taylor Obstetrical and Gynecological Pathology. Edited By H. Fox and M Wells. Vol.1. Churchill Livingstone. Fourth Edition. 1995; 712-713.

6. Crump Ch. Robbins. The Female Genital Tract in: Robbins Pathologic Basis of Disease. Saunders. Sixth Edition. 1999; 1066.
7. Young RH, Scully RE. Non-neoplastico disorders of the ovary; in Haines \& Taylor Obstetrical and Gynecological Pathology. Edited By H. Fox and M Wells. Vol.1. Churchill Livingstone. Fourth Edition. 1995; 699-701.

8. MacDonald HN, Buckler JMH, Scott JS. Human chorionic gonadotropin levels during and after labour. British Journal of Obstetrics and Gynecology. 1974; 81: 371-373.

9. Pastorfide GB, Goldstein DP, Kosasa TS, Levesque L. Serum chorionic gonadotropin activity after molar pregnancy, therapeutic abortion, and term delivery. American Journal of Obstetrics and Gynecology. 1974; 118: $293-$ 294.

10. Clement PB, Young RH, Scully RE. Ovarian granulosa cell proliferations of pregnancy: a report of nine cases. Human Pathology. 1988; 19: 657-662. 